\title{
ASSESSING COMPREHENSIVE SECURITY APPROACHES IN ACTION: AN INTRODUCTION
}

$\mathrm{T}$

The broadening, deepening and widening of the security concept has been well rehearsed over the past three decades, both inside and outside of academia. It security have enriched academic as well as policy discourses that previously evolved around national security. ${ }^{1}$ Whether as a symptom or as a result of this development, European governments now identify a broad range of interests beyond territorial and physical security in their national security strategies. The inclusion of social, cultural, economic and environmental concerns is the rule rather than the exception. In this context, it is bon ton amongst policy actors to assert that the plethora of complex security challenges faced by our societies can only be addressed within comprehensive security approaches. ${ }^{2}$

The European Commission, as one of these actors, describes for instance in its April 2015 communication on the European Security Agenda "a shared approach for the EU and its Member States that is comprehensive, results-oriented and realistic," and continues to use the term four more times. ${ }^{3}$ At the European level, the term 'comprehensive approach' typically refers to closer coordination and collaboration between agencies and member states, and is applied both with respect to internal and external policies. ${ }^{4}$ Amongst individual member states there is general agreement that a comprehensive security approach refers to bringing a broad range of policy instruments to address challenges in a coordinated manner, even if differences remain with respect to its actual operationalisation. ${ }^{5}$ The comprehensive security approach has thus captured the imagination of policymakers across Europe for quite some time. More recently, the track record of comprehensive security policies has been garnering increasing attention. Much of the attention has been dedicated to the design as well as the implementation of the comprehensive approach in external security policies, which many observers find to be flawed on both counts. ${ }^{6}$

The current special issue seeks to contribute to the debate about the further development of the comprehensive security approach by shifting the focus towards its appli- 
cation in an internal European context. It starts out with a critical reflection on the utility of the comprehensive security concept for policymakers followed by an eclectic collection of critical analyses and case studies of various aspects of comprehensive security, drawn from numerous European countries, including Bulgaria, Italy, Serbia and Turkey.

The papers vary considerably both in topical focus and methodological approach (which only reflects the inherent broadness of the subject under investigation), while many of them also share a number of key premises, five of which are worth listing here in the introduction.

1. While the provision of security remains a key task of states, a comprehensive security approach needs to involve citizens, both for reasons of effectiveness and legitimacy. The first paper by Iztok Prezelj ${ }^{7}$ raises doubts about the utility of comprehensive security for policymaking partially because of obstacles to its implementation in practice. The involvement and education of citizens in its implementation-while certainly not a panacea - may help overcome some of these obstacles.

2. Security concerns are dynamic rather than static. The constant feedback loop between security challenges and security concerns therefore requires security policies that are adaptive by design. Antoniya Todorova's analysis of the evolution of the Kurdish question in the Turkish security discourse can be read in this context, ${ }^{8}$ and so can Nikolic's paper about Serbian security perceptions and citizens' motivations to serve in the armed forces. ${ }^{9}$

3. Comprehensive security policies need to be multilayered and multifaceted, targeting not only material realities but also perceptions. Matteo Bonfanti and Francesca Capone illuminate the importance of such a multi-track approach in a case study of CBRN crisis management practices in eleven European countries. ${ }^{10}$

4. Comprehensive security policies need to consciously integrate soft and hard approaches. Valeri Ratchev, Vesselin Petkov and Todor Tagarev take a closer look at this aspect in the case of Bulgaria. ${ }^{11}$

5. Comprehensive security policies acknowledge that ethical and moral issues are inextricably intertwined with security and cannot be seen in isolation from one another. The paper by Francesca Vietti and Roberto Franzini Tibaldeo highlights the ethical and moral dimensions in their case study of Syrian asylum seekers. ${ }^{12}$

Of course, each of the papers in this issue elaborates one or more of these five premises more fully, and each paper in its own way provides relevant insights for the further development of the comprehensive security approach. 
This special issue has been conceived in the framework of the Evolving Concepts of Security project (EvoCS) funded by the European Commission. At the heart of the EvoCS project lies the conviction that security policies need to be both effective and considered legitimate in the eyes of stakeholders they are intended to serve. Within EvoCS, a multinational consortium of researchers therefore executed twelve comparative and comprehensive country case studies of prevailing security concerns across four European regions. The case studies not only mapped the salient security concerns and security challenges as perceived by different national stakeholders, but also looked at the principal actors and the levels of action, as well as the key ethical and human rights issues identified in these security discourses. ${ }^{13}$ The findings of the case studies are intended to ensure representative input of European security concerns to the evolving security agenda of the European Commission.

In the final contribution to this special issue, Daniela Lieberz scrutinises the results of the EvoCS project in a series of quantitative tests. ${ }^{14}$ She analyses the coding results from five of the twelve country studies and ascertains their statistical consistency. She reaches similar conclusions, ${ }^{15}$ but goes beyond the qualitative analysis undertaken within the EvoCS project, to cluster the 'core values' in what she defines as three 'basic principles' in studying security perceptions: freedom from want (linked to economic and environmental aspects); freedom from instability (linked to political, social and territorial aspects), and freedom from fear (linked to physical safety), the last one seemingly the most critical at the moment.

The study by Dr. Lieberz demonstrates the richness and the value of the raw data generated by EvoCS. Our intention is to provide the project-generated data to researchers interested to validate - or disprove - our findings or re-use it for other purposes. The further exploration of the EvoCS data-set will enhance the common knowledge and understanding of the evolving concepts of security across Europe.

We hope that you enjoy reading this special issue.

The guest editors

Tim Sweijs \& Milos Jovanovic

\section{Notes}

${ }^{1}$ Richard H. Ullman, "Redefining Security," in International Security 8, no. 1 (1 July 1983): 129-53, http://dx.doi.org/10.2307/2538489; UNDP, “New Dimensions of Human Security," in Human Development Report 1994, available at http://hdr.undp.org/en/content/humandevelopment-report-1994; Barry Buzan, Ole Wæver and Jaap de Wilde, Security: A New Framework for Analysis (Lynne Rienner Publishers, 1998); Esther Brimmer, "From Territorial Security to Societal Security: Implications for the Transatlantic Strategic 
Outlook," in Transforming Homeland Security: U.S. and European Approaches (Center for Transatlantic Relations, Paul H. Nitze School of Advanced International Studies, Johns Hopkins University, 2006); J. Peter Burgess, Handbook of New Security Studies (Routledge, 2010).

${ }^{2}$ For the evolution of the use of the term by European policymakers over time, see Sven Biscop and Rik Coolsaet, "The World Is the Stage: A Global Security Strategy for the EU," Groupement d'Etudes et de Recherches "Notre Europe," Policy Paper, no. 8 (2003), available at http://www.delorsinstitute.eu/011-788-The-world-is-the-stage-a-global-securitystrategy-for-the-European-Union.html; ETTIS (European Security Trends and Threats in Society), "Deliverable 1.1. Conceptual Foundations of Security," 2012, 1-147, available at http://ettis-project.eu/wp-content/uploads/2012/03/D1_12.pdf.

3 European Commission, "The European Agenda on Security," 28 April 2015, available at http://eur-lex.europa.eu/legal-content/EN/TXT/HTML/?uri=CELEX:52015DC0185\&rid=1.

${ }^{4}$ High Representative of the EU for Foreign Affairs and Security Policy and the European Commission, "The EU's Comprehensive Approach to External Conflict and Crisis, Joint Communication to the European Parliament and the Council," 11.12.2013, JOIN (2013) 30 final, available at http://www.eeas.europa.eu/statements/docs/2013/131211_03_en.pdf.

5 For the similarities and differences in interpretations of national governments in an external context, see Margriet Drent, "The EU's Comprehensive Approach to Security: A Culture of Co-Ordination?," Studia Diplomatica 64, no. 2 (2011): 3-4.

${ }^{6}$ See for instance Fernanda Faria, "What EU Comprehensive Approach? Challenges for the EU Action Plan and Beyond," accessed 15 October 2015, available at http://ecdpm.org/wpcontent/uploads/BN71-What-EU-Comprehensive-Approach-October-2014.pdf. For the Commission, see High Representative of the EU for Foreign Affairs and Security Policy and the European Commission, "The EU's Comprehensive Approach to External Conflict and Crisis, Joint Communication to the European Parliament and the Council," and for an overview of gaps between member states and the EU, see Volker Hauck and Camilla Rocca, "Gaps between Comprehensive Approaches of the EU and EU Member States," 12 May 2014, available at http://ecdpm.org/wp-content/uploads/Gaps-Between-ComprehensieveApproach-of-the-EU-and-EU-Member-States.pdf.

7 Iztok Prezelj, "Comprehensive Security and Some Implemental Limits," Information \& Security: An International Journal 33 (2015): 13-34, http://dx.doi.org/10.11610/isij.3301.

8 Antoniya Todorova, "Turkish Security Discourses and Policies: The Kurdish Question," Information \& Security: An International Journal 33 (2015): 108-21, http://dx.doi.org/ 10.11610/isij.3305.

9 Nebojsa Nikolic, "Serbian Security Perceptions: Motivations to Serve," Information \& Security: An International Journal 33 (2015): 122-37, http://dx.doi.org/10.11610/isij.3306.

${ }^{10}$ Matteo E. Bonfanti and Francesca Capone, "Fostering a Comprehensive Security Approach: An Exploratory Case Study of CBRN Crisis Management Frameworks in Eleven European Countries," Information \& Security: An International Journal 33 (2015): 55-80, http://dx.doi.org/10.11610/isij.3303.

${ }^{11}$ Valeri Ratchev, Vesselin Petkov and Todor Tagarev, "Evolving Security Concepts: The Premium on Governance in the Case of Bulgaria," Information \& Security: An International Journal 33 (2015): 83-107, http://dx.doi.org/10.11610/isij.3304.

${ }^{12}$ Francesca Vietti and Roberto Franzini Tibaldeo, "A Human Rights and Ethical Lens on Security and Human Dignity: The Case Study of Syrian Asylum Seekers," Information \& Security: An International Journal 33 (2015): 35-53, http://dx.doi.org/10.11610/isij.3302.

${ }^{13}$ More information on the findings and the method can be found on the EvoCS website at http://evocs-project.eu/. 
${ }^{14}$ Daniela Lieberz, "Multivariate Statistics of Security Perceptions in Europe," Information \& Security: An International Journal 33 (2015): 138-66, http://dx.doi.org/10.11610/isij.3307.

${ }^{15}$ The forthcoming Deliverable D9.1 will be publically available at http://dx.doi.org/ 10.11610/evocs.91 and interested readers will be able to compare findings as a result of qualitative and quantitative analysis.

Tim SWEIJS is a researcher at the Hague Centre for Strategic Studies (HCSS, www.hcss.nl). He is the initiator, creator and author of numerous studies, methodologies, and tools for research projects in horizon scanning, conflict analysis, international and national security risk assessment, and capability development. Tim has led multicentre research projects for both private and public sector organisations - including the European Commission and various European governments. He spearheads the HCSS StratMon program which offers strategic assessments of medium to long term risks in the global security environment to the Strategic Monitor of the Dutch Ministries of Defence, Foreign Affairs and Security and Justice. Tim has lectured at civilian universities and military academies around the world. Prior to HCSS, he was a researcher at TNO Defence and Security in The Hague and at the research staff of NATO's Parliamentary Assembly in Brussels. Tim received degrees in War Studies (MA, merit, King's College), International Relations (MSc, cum laude, University of Amsterdam) and Philosophy (BA, cum laude, University of Amsterdam). E-mail:TimSweijs@hcss.nl.

Dr. Milos JOVANOVIC studied modern history, political science, media science and information science at the Heinrich-Heine University in Düsseldorf (MA). He joined the Fraunhofer Institute for Technology Trend Analysis (Fraunhofer INT, Germany, www.int.fraunhofer.de/en.html) as a PhD student in 2006, finishing his $\mathrm{PhD}$ thesis in 2011 (Magna cum laude). His current activities are focused on bibliometrics, innovation management, methods of technological forecasting, planning processes, strategies and projects in the field of R\&T related to security and defence. He is a lecturer at the Heinrich-Heine University, where he gives classes on project management and bibliometrics. Dr. Jovanovic is the Coordinator of the EvoCS project and deputy head of unit of the "International Research and Technology Management" group at the Fraunhofer INT. E-mail: Milos.Jovanovic@int.fraunhofer.de. 